\title{
EDUCATION
}

\section{Positivity, Coping Style and Tobacco and Alcohol Use in Adolescence}

\section{Dolores Lara, José Bermúdez \& Ana M. Pérez-García}

Facultad de Psicología, UNED, Madrid

\section{Spain}

Correspondence: José Bermúdez. Facultad de Psicología, UNED. c/ Juan del Rosal, 10, 28040 Madrid. España. E-mail: jbermudez@psi.uned.es

(C) Education \& Psychology I+D+i and Editorial EOS (Spain) 


\section{Abstract}

Introduction. Adolescence is a period when at-risk health behaviors often begin, such as tobacco and alcohol use; thus, it is a critical period for implementing preventive strategies.

Method. In this context, 106 adolescents took part in this research (54 females and 52 males; mean age for both groups $=14.10$ ). The main objectives were to first study the relationships between psychosocial factors, such as coping style and the new construct of positivity, and tobacco and alcohol use; then to analyze the potential effect of gender and age differences.

Results. Results revealed (1) significant relationships among coping, positivity, and substance use; (2) that these effects were modulated by age and gender, and (3) that positivity was one of the most significant predictors of tobacco and alcohol use, having a protective role.

Conclusion. Results concerning the contribution of coping style, age and gender in explaining adolescents' tobacco and alcohol use tend to be consistent with previous research on this topic. On the other hand, results regarding the positivity dimension constitute a novel contribution to the research in this area, suggesting its significant protective role against the development of risk behaviors such as tobacco and alcohol use.

Keywords: Positivity, Adolescence, Coping, Tobacco, Alcohol

Received: 04/15/13 Initial acceptance: $05 / 10 / 13 \quad$ Final acceptance: 07/14/13 


\section{Positividad, Estilo de Afrontamiento y Consumo de Tabaco y Alcohol en la Adolescencia}

\section{Resumen}

Introducción. La adolescencia es una etapa crítica para actuar a nivel preventivo, teniendo en cuenta que en ella suelen iniciarse conductas de riesgo para la salud, como el consumo de tabaco y alcohol.

Método. En este contexto, 106 adolescentes (54 chicas y 52 chicos; edad media de 14,10 años, tanto en chicos, como en chicas) participaron en esta investigación, cuyos objetivos fueron analizar las relaciones que mantienen el estilo de afrontamiento y la positividad con el consumo de tabaco y alcohol, así como las posibles diferencias debidas al sexo y la edad.

Resultados. Los resultados mostraron, primero, la presencia de relaciones significativas entre estilo de afrontamiento, positividad y consumo de tabaco y alcohol; segundo, el papel modulador de la edad y el sexo; finalmente, la positividad fue uno de los factores predictivos más significativos del consumo de alcohol y tabaco, destacando su papel protector.

Conclusión. Los resultados relativos a la significación del estilo de afrontamiento, la edad y el género en la explicación del consumo de tabaco y alcohol en la adolescencia, tienden a ser consistentes con la investigación existente sobre el tema. Suponen, al mismo tiempo, una aportación novedosa a la investigación en este ámbito los resultados relativos a la dimensión de positividad, que sugieren su significativo papel protector ante el desarrollo de conductas de riesgo como las consideradas en nuestro estudio.

Palabras Clave: Positividad, Adolescencia, Afrontamiento, Tabaco, Alcohol 


\section{Introduction}

Adolescence is essentially a period of change and of certain instability, associated with a search for identity and personal autonomy, and with greater susceptibility to social influence. Taking into account that this period of life is also when risk behaviors typically begin, particularly the use alcohol and tobacco, adolescence is a critical period for preventive action.

Data from Spain's State Survey on Drug Use in Secondary Students (ESTUDES 2008) and Health Behavior in School-aged Children (HBSC) (cited in the extended summary in Ramos \& Moreno, 2010) indicate that alcohol and tobacco continue to be the drugs most often used by Spanish students between the ages of 14 and 18, even though their use seems to have stabilized in 2009, in consonance with the observed trend in other southern Europe countries.

More recently, and in more detail, data from ESTUDES 2010 (Plan Nacional sobre Drogas, 2010), on adolescent use of tobacco and alcohol, reveal that $75.1 \%$ of Spanish adolescents have consumed alcohol on some occasion, 73.6\% have done so in the past 12 months, and $63 \%$ in the past month, with the mean age for initiation at 13.7 years. Prevalence of use is somewhat higher in girls than in boys; however, when the data is broken down by gender and age, prevalence of use is observed to be greater in girls between the ages of 14 and 16, while at 17-18 years of age the percentage of males that consume alcohol is superior to that of females. Finally, prevalence of use tends to increase with age. Thus, $38.1 \%$ of 14-year-olds claim to have consumed alcohol in the past month, while that percentage rises to $77.1 \%$ of adolescents at age 18 .

After alcohol, tobacco is the most prevalent drug used by secondary students in Spain. $39.8 \%$ have smoked at some time in their life, and $26.2 \%$ have done so in the past month. In the past year, a greater number of girls have smoked than boys (36.4\% vs. 28.1\%); however, the latter consumed a larger number of cigarettes $(11.7 \%$ of the boys reported smoking more than 10 cigarettes a day, compared to $7.6 \%$ of the girls). The mean age for starting to smoke is 13.5 years. Finally, smoking tends to increase with age for both males and females, going from $12.3 \%$ in 14 -year-olds to $40 \%$ in the 18 -year-olds. 
In this context, a growing volume of research focuses on identifying psychosocial factors that might explain the initiation and continuation of substance use in adolescence, for the purpose of designing strategies to prevent its appearance and development. Among these factors, behavior styles deserve particular attention, such as the type of strategies that the adolescent uses when facing difficulties (Lazarus \& Folkman, 1986; Parker \& Endler, 1996), as well as cognitive factors, positive general expectations that express how a person perceives and values himself or herself and the different facets of their life, as well as their stance toward the future; cognitive processes belonging to the constructs of self-esteem (Emler, 2001; Rosenberg, 1965), optimism (Carver \& Scheier, 2002; Scheier \& Carver, 1985) and life satisfaction (Diener, 1984), respectively.

In the research on coping strategies, two large classes of interrelated strategies are usually distinguished: on one hand are emotion-centered strategies that attempt to regulate the emotional response to the problem, and on the other hand, problem-centered strategies attempt to address and respond to the problem that is causing stress (Carver \& Connor-Smith, 2010; Lazarus \& Folkman, 1986).

Studies regarding the use of such strategies in adolescence show that the adolescent tends to use a set of preferred strategies in a more or less stable fashion in order to face specific problems, and that his or her repertoire of strategies increases with age. However, despite certain ambiguity in the research results, this overall pattern seems to be modulated by factors such as the subject's gender and age. Available evidence on gender differences tends to show that girls have a greater number of coping strategies, with greater use of strategies based on contact with others, such as seeking social support, confiding in friends and seeking to belong. Boys, for their part, use more unproductive coping strategies, such as seeking distraction, ignoring the problem or keeping it to themselves. Research on age-related differences tends to indicate that use of unproductive coping strategies increases with age, such as blaming oneself or trying to reduce tension; while in the early stages of adolescence, there is greater use of avoidance and social support (Gómez-Fraguela, Luengo, Romero, Villar \& Sobral, 2006; González-Barrón, Montoya, Casullo \& Bernabéu, 2002; Martín, Lucas \& Pulido, 2011).

Other research addresses the role of coping styles as protective factors or as risk factors of substance use in adolescence. The available evidence points to strategies such as mak- 
ing an effort, concentrating on problem solving, and thinking positively, as having protecting effects in preventing substance use, while use of avoidance strategies when faced with problems encourages substance use (Gómez-Fraguela et al., 2006; Myers \& MacPherson, 2009).

Research on the role of self-esteem, life satisfaction and optimism in explaining substance use is guided by the common assumption that positive general expectations play an important role in self-regulation of behavior, and are associated with use of adaptive coping strategies (Scheier \& Carver, 1985), thus acting as protective elements against risk behaviors (Carvajal, 2012; Carvajal, Evans, Nash \& Getz, 2002).

Regarding self-esteem, which is the feeling of self-acceptance and regard, of competence and personal worth (Rosenberg, 1965), there is sufficient evidence to date to indicate its beneficial role as a determinant in physical and psychological well-being (Emler, 2001). In the area of substance use, the evidence consistently points to self-esteem as a significant predictor of initiation and frequency of use, where greater self-esteem is associated with less likelihood of becoming a smoker (Otten, van Lier \& Engels, 2011), even though this association tends to be more pronounced in girls than in boys (Abernathy, Massad \& RomanoDwyer, 1995). The possible presence of gender- and age-related individual differences in selfesteem has generated a significant volume of research, indicating that women tend to present lower levels of self-esteem than men, although these differences are small and are mainly observed in adolescence (see the meta-analyses from Kling, Hyde, Showers \& Buswell, 1999; Major, Barr, Zubek \& Babey, 1999; Twenge \& Campbell, 2001). Nonetheless, in order to correctly understand this evidence, one must keep in mind that it stems from research that evaluates self-esteem as a global construct; when specific facets of self-esteem are analyzed (social acceptance, physical appearance, personal assessment and satisfaction, ethical-moral dimension of behavior, etc.), the differential profile of boys and girls in different stages of development changes substantially, and no longer appears to be as linear and homogeneous as seen in research on the global construct (Gentile, Grabe, Dolan-Pascoe, Twenge \& Wells, 2009).

Similarly, life satisfaction, feeling satisfied with oneself and with life itself (Diener, Emmons, Larsen \& Griffin, 1985), contributes positively to the perception of personal wellbeing, protects physical and psychological health, and is associated with adaptive coping styles directed at solving problems (Diener \& Chan, 2011; González-Barrón et al., 2002). 
While the available evidence in the adult population tends to indicate that men report higher levels of life satisfaction, data on the adolescent population are less conclusive; as for age, life satisfaction tends to decrease in this age range, although this trend is affected by the different domains that make up life satisfaction (academic, heatlh, friends, family, etc.) (Gilman et al., 2008; Goldbeck, Schmitz, Besier, Herschbach \& Henrich, 2007). Research on the association between life satisfaction and substance use, with adolescent samples, concludes that low levels of life satisfaction influence both the early start of substance use, as well as later abuse of substances such as alcohol and tobacco (Masferrer, Font-Mayolas \& Gras, 2012; Piko, Luszczynska, Gibbons \& Teközel, 2005; Zullig, Valois, Huebner, Oeltmann \& Drane, 2001).

A similar pattern of results can be expected from optimism, in the sense that persons with positive expectations about the future usually present healthier behavior styles and respond more adaptively to difficulties, than do persons with negative expectations (Carver, Scheier \& Segerstrom, 2010; Scheier \& Carver, 1985). On the other hand, research on genderrelated differences in optimism among adolescents still offers inconclusive results: while some studies indicate that males present higher levels of optimism than females (Bindorf, Ryan, Auinger \& Aten, 2005; Puskar et al., 2010), other studies find no significant genderrelated differences (Boman, Smith \& Curtis, 2003; Huan, Yeo, Ang \& Chong, 2006). Finally, the available evidence on a possible differential effect of age tends to show a notable stability in dispositional optimism over one's life span, although fluctuations and peculiarities are naturally observed in association with specific circumstances that a person experiences (Carver \& Scheier, 2002; Glaesmer et al., 2012).

In this context, the construct positivity was recently suggested to account for the significant interrelationship between self-esteem, optimism and life satisfaction, and for their effects on the most diverse spheres of life and behavior (health, emotionality, performance, coping style, interpersonal relationships, etc.) (Alessandri, Vecchione et al., 2012; Caprara, Steca, Alessandri, Abela \& McWhinnie, 2010). Positivity can be conceptualized as the predisposition toward basic, relatively stable and culturally generalized behavior that underlies self-esteem, optimism, and life satisfaction, thereby explaining a greater percentage of the variance in behavior than what is attributed to these expectations taken individually or jointly. In other words, it may be said that positivity represents a significant determining factor in the optimal functioning of persons, and even though further research is required on possible differences in this construct due to gender and age, data that are currently available suggest a 
similar profile to that of the constructs that are incorporated therein (Alessandri, Caprara \& Tisak, 2012; Caprara, Alessandri, Eisenberg et al., 2012; Caprara, Alessandri, Trommsdorff et al., 2012).

\section{Objectives}

In summary, keeping in mind the significant role of coping styles in initiating and continuing substance use in adolescence, the possible effect of gender- and age-related differences, as well as the high expectations around the new construct of positivity (as yet to be embraced in the research of Spain), the present study poses the following objectives: 1) Study the relations between positivity, coping style and tobacco and alcohol use, as well as possible differences due to gender and age; 2) Analyze the predictive contribution from the different factors in tobacco and alcohol use.

In order to meet these objectives, the following hypotheses are tested in this study: first, tobacco and alcohol use is associated with low levels of positivity and the use of unadaptive coping strategies; second, the relationship between positivity, coping style and tobacco and alcohol use will be modulated by differences in gender and age, where substance use is expected to increase with age, especially in the boys.

\section{Method}

\section{Participants}

The initial sample was composed of 107 Spanish adolescents (55 girls and 52 boys), with a mean age of 14.10 años, for both boys and girls ( $\mathrm{SD}=0.98$; range 12-17). One girl was eliminated from the study sample since she did not correctly complete all the tests in the assessment booklet. The participants were students in the $2^{\text {nd }}$ and $3^{\text {rd }}$ year of compulsory secondary education, or in the first year of individual vocational training at a secondary school in the province of Huelva (Spain).

\section{Instruments}

The Brief COPE (Carver, 1997; a version of the Spanish adaptation, from Morán, Landero \& González, 2010) was used to assess coping. It contains 14 scales with two items each: Active coping, Planning, Positive reevaluation, Acceptance, Humor, Spirituality, Use of 
emotional support, Use of instrumental support, Self-distraction, Denial, Venting of emotions, Substance use, Giving up and Blaming Self. The scales show reliabilities between 0.50 and 0.90. In fact, only three of them present reliabilities less than 0.60 (Acceptance, Denial and Venting of emotions). This coping inventory provides researchers with a quick way to assess potentially important coping responses, some of them adaptive and others more problematic. Carver (1997) indicates that researchers can select those scales that are of greater interest for the samples that they are going to analyze and for the specific objectives of each study. The response format is a 4-point, frequency of use scale, from 0 (almost never) to 3 (almost always).

Our study took only one item from each subscale, following a strategy used by other authors (Eisenberg, Shen, Schwarz \& Mallon, 2012), to keep the test from being unnecessarily long with very redundant items. Items were re-written to adapt them for use with an adolescent population (e.g., for a self-distraction strategy, "browsing Internet or playing console games" was substituted for "going shopping") and instructions were of a dispositional nature, asking how one generally reacts when encountering difficult situations, problems or troubles.

The Positivity Scale (Caprara, Alessandri, Eisenberg et al., 2012) was used to measure positive orientation. It is made up of 8 items that measure aspects associated with the three large constructs of Self-esteem, Optimism and Life Satisfaction, with items such as "I feel I have lots of things to be proud of", "I look to the future with hope and optimism", and "I am satisfied with my life". These items assess a person's tendency to see life and to direct their experiences with a positive orientation. The instructions ask the subject to indicate on a scale of 5 points (from 1 to 5) the degree to which they agree with the content of each item. Scale reliability in this sample was 0.80 , similar to what was reported by their author in other studies with samples from different countries (Caprara et al., 2012). High scores indicated greater positivity.

Tobacco and alcohol use was measured with two items having four possible responses. The first item asked, "How many cigarettes do you smoke per day?", with responses reported on a four-point scale of 1 (do not smoke), 2 (from 1 to 10 cigarettes), 3 (from 11-20 cigarettes) and 4 (more than 20). The second item asked, "How many times per week do you drink alcoholic drinks?, where 1 is never, 2 is once, 3 is twice, and 4 is three times or more. In both cases, higher scores indicate greater use. 


\section{Procedure}

The research process and objective were explained in detail to the school's Guidance Counselor, attaining his approval as well as informed consent from the parents of minors participing in the study. The tests were administered during core class periods, with both the mainstream teacher and the researcher in attendance. The researcher explained to the group what the upcoming task consisted of, as well as its objective. Students were asked to respond sincerely, and were assured of the confidentiality of their responses. Once instructions were given, each student individually completed the tests that had been presented.

\section{Data Analysis}

The Pearson correlation was used as an index of linear relation between the variables. A multivariate analysis of variance (MANOVA) was done next, with Wilks' Lambda criterion for significance, in order to test the main effects between the variables (positivity and gender) and the possible interaction between them, so as to later analyze such multivariate effects through univariate analyses of variance (ANOVAs). Finally, multiple regression analysis was used with the stepwise method in order to find the most significant, best adjusted model for the sample size, in order to determine prediction indices of these variables for tobacco and alcohol use.

\section{Results}

\section{Descriptive and correlational data}

As seen in Table 1, the mean value of positivity in the sample indicated a medium-high score, if we consider that the possible range in this scale is from 8 to 40 . Regarding coping strategies, whose real values could range from 0 to 3, medium and high scores were obtained. The highest scores were seen in cases of active coping, positive reevaluation, use of emotional support, use of instrumental support, and especially self-distraction. The lowest values were obtained for strategies of substance use, spirituality, giving up and denial. 
Table 1. Mean (and standard deviations) of the variables measured in this study, as well as their correlation with positivity, tobacco use and alcohol use $(\mathrm{N}=106)$

\begin{tabular}{lcccc}
\hline \multicolumn{1}{c}{ Variables } & Mean (SD) & Positivity & Tobacco & Alcohol \\
\hline Positivity & $32.04(4.71)$ & -- & -- & -- \\
Tobacco use & $1.17(0.49)$ & $-0.32^{* * *}$ & -- & -- \\
Alcohol use & $1.35(0.59)$ & $-0.30^{* *}$ & $0.36^{* * *}$ & -- \\
\hline Active Coping & $2.08(0.89)$ & $0.25^{* *}$ & -0.01 & -0.08 \\
Planning & $1.88(0.90)$ & $0.24^{* *}$ & -0.06 & -0.17 \\
Positive Reevaluation & $2.19(0.90)$ & $0.20^{*}$ & 0.08 & 0.07 \\
Acceptance & $2.03(0.93)$ & 0.10 & -0.03 & -0.05 \\
Humor & $1.25(1.15)$ & 0.07 & -0.02 & 0.07 \\
Spirituality & $0.44(0.80)$ & 0.10 & 0.05 & $0.24 *$ \\
Use of Emotional Support & $2.29(0.93)$ & 0.15 & -0.17 & -0.14 \\
Use of Instrumental Support & $2.12(0.90)$ & 0.08 & -0.05 & 0.03 \\
Self-distraction & $2.40(0.89)$ & $0.21 *$ & -0.05 & 0.04 \\
Denial & $0.75(0.99)$ & -0.08 & 0.11 & $0.28^{* *}$ \\
Venting of emotions & $1.35(1.09)$ & -0.03 & 0.15 & 0.11 \\
Substance use & $0.28(0.71)$ & $-0.22^{*}$ & $0.52 * * *$ & $0.63 * * *$ \\
Giving up & $0.66(0.82)$ & -0.12 & -0.05 & 0.03 \\
Blaming self & $1.21(0.97)$ & $-0.28^{* *}$ & -0.04 & 0.11 \\
\hline Note: $*$ p $0.05 ; * *<0.01 ; * * *<0.001$ & & & &
\end{tabular}

Positivity was positively related to Active Coping, Planning, Positive Reevaluation and Self-distraction, and negatively related to strategies of Substance use and Blaming Self, as well as to drinking and smoking behaviors. These two behaviors were related to each other, in addition to a positive relationship with the strategy of Substance use, and with age (smoking = $0.30, p<.01$; drinking $=0.20, p<.05)$. The behavior of drinking alcohol was positively correlated with the strategies of Denial and Spirituality (see Table 1).

A distribution analysis of substance use indicated that $29.3 \%$ of the sample consumed alcohol and $13.2 \%$ smoked. Among those that consumed alcohol, 23.6\% drank at least once a week, and among those that smoked, the largest group (10.4\%) consumed between 1 and 10 cigarettes a day. 
Study of positivity and gender in coping and in tobacco and alcohol use

Groups of highs and lows were formed according to their scores on the Positivity scale, as defined by the median value $(\mathrm{Mdn}=33)$. Participants who obtained a score of 33 or less were considered low in positivity ( 24 boys and 32 girls), and the highs in positivity were those who scored between 34 and 40 ( 28 boys and 22 girls). We verified, first of all, that there were no age-related differences either for level of Positivity $[F(1,105)=0.36]$ or as a function of gender $[F(1,105)=0,03]$.

The multivariate analysis of variance (MANOVA) showed that the combined variables (coping and substance use) were significantly affected by positivity [Wilks' $\lambda=0.73$; $\mathrm{F}(16,87)=2.05, p<.02 ; \eta 2 \mathrm{p}=0.273$ ] and by gender [Wilks' $\lambda=0.33 ; F(16,87)=2.63, p<.02$; $\eta 2 p=0.326$ ], but not by the interaction between the two factors [Wilks' $\lambda=0.85 ; F(16,87)=$ $1.01, p=0.469 ; \eta 2 p=0.155]$.

The univariate analyses (see Table 2) showed that the highs in positivity reported greater use of the strategies of Active Coping, Planning, Positive Reevaluation, Spirituality, Support (both instrumental and emotional) and Self-distraction, and they smoked less than the lows in positivity. As for gender, the girls used social support strategies significantly more than the boys, whether emotional or instrumental, as well as venting of emotions.

Table 2. Means (standard deviation in parentheses), univariate analysis of variance and effect size $\left(\eta_{p}^{2}\right)$ of variables Positivity and Gender on coping strategies and use of tobacco and alcohol

\begin{tabular}{|c|c|c|c|c|c|c|c|c|}
\hline \multirow{3}{*}{ Variables } & \multicolumn{4}{|c|}{ Positivity } & \multicolumn{4}{|c|}{ Gender } \\
\hline & High & Low & & & Boys & Girls & & \\
\hline & $(\mathrm{n}=50)$ & $(n=56)$ & $\mathrm{F}(1,105)$ & $\eta_{p}^{2}$ & $(n=52)$ & $(n=54)$ & $\mathrm{F}(1,105)$ & $\eta_{p}^{2}$ \\
\hline Active Coping & $2.30(0.81)$ & $1.89(0.91)$ & $6.06^{*}$ & 0.06 & $2.06(0.968)$ & $2.11(0.82)$ & 0.41 & 0.00 \\
\hline Planning & $2.16(0.87)$ & $1.62(0.87)$ & $10.01 * *$ & 0.09 & $1.90(0.89)$ & $1.85(0.92)$ & 0.00 & 0.00 \\
\hline Positive Reeval. & $2.44(0.79)$ & $1.96(0.93)$ & $8.40^{*}$ & 0.08 & $2.15(0.83)$ & $2.41(0.85)$ & 0.52 & 0.01 \\
\hline Acceptance & $2.10(0.93)$ & $1.96(0.93)$ & 0.71 & 0.01 & $1.96(0.95)$ & $2.09(0.92)$ & 0.67 & 0.01 \\
\hline Humor & $1.26(1.19)$ & $1.23(1.13)$ & 0.00 & 0.00 & $1.37(1.12)$ & $1.13(1.18)$ & 1.19 & 0.01 \\
\hline Spirituality & $0.62(0.97)$ & $0.29(0.56)$ & $5.35 *$ & 0.05 & $0.38(0.72)$ & $0.50(0.86)$ & 1.13 & 0.01 \\
\hline Emotional Support & $2.46(0.84)$ & $2.14(0.99)$ & $5.65^{*}$ & 0.05 & $2.00(1.09)$ & $2.57(0.66)$ & $12.91 * * *$ & 0.11 \\
\hline Instrumental Support & $2.28(0.78)$ & $1.98(0.98)$ & $5.44 *$ & 0.05 & $1.85(0.98)$ & $2.36(0.79)$ & $12.38 * * *$ & 0.11 \\
\hline Self-distraction & $2.58(0.73)$ & $2.23(0.97)$ & $4.68 *$ & 0.04 & $2.35(0.97)$ & $2.44(0.79)$ & 0.64 & 0.01 \\
\hline Denial & $0.80(1.01)$ & $0.71(0.97)$ & 0.38 & 0.00 & $0.63(0.93)$ & $0.87(1.03)$ & 1.55 & 0.02 \\
\hline Venting of emotions & $1.38(1.07)$ & $1.32(1.11)$ & 0.91 & 0.01 & $0.88(1.00)$ & $1.80(0.98)$ & $22.75^{* * *}$ & 0.18 \\
\hline$-356-$ & Electronic & $\begin{array}{l}1 \text { of Resear } \\
\text { http://dx }\end{array}$ & $\begin{array}{l}\text { Educatio } \\
\text { g/10.142 }\end{array}$ & $\mathrm{ycl}$ & $\begin{array}{l}y, 11(2), 345 \\
3036\end{array}$ & ISSN: 1696 & 2013, no. 30 & \\
\hline
\end{tabular}




\begin{tabular}{lllllllll} 
Substance use & $0.26(0.72)$ & $0.30(0.71)$ & 0.15 & 0.00 & $0.33(0.73)$ & $0.24(0.70)$ & 0.50 & 0.01 \\
Giving up & $0.56(0.79)$ & $0.75(0.86)$ & 1.23 & 0.01 & $0.62(0.79)$ & $0.70(0.86)$ & 0.14 & 0.00 \\
Blaming self & $1.10(0.95)$ & $1.30(0.97)$ & 0.75 & 0.01 & $1.04(0.91)$ & $1.37(0.99)$ & 2.72 & 0.03 \\
\hline Smoking & $1.06(0.24)$ & $1.27(0.62)$ & $4.56^{*}$ & 0.04 & $1.13(0.49)$ & $1.20(0.49)$ & 0.21 & 0.00 \\
Drinking & $1.30(0.54)$ & $1.39(0.62)$ & 0.80 & 0.01 & $1.38(0.60)$ & $1.31(0.58)$ & 0.50 & 0.01 \\
\hline
\end{tabular}

Note: $* p<0.05 ; * * p<0.01 ; * * * p<0.001$

Variables predicting substance use

Two stepwise multiple regression analyses were carried out, taking tobacco and alcohol use as dependent or criterion variable, and taking gender, age (given that it correlates significantly with greater use), positivity and coping strategies as predictive variables (Table 3). (The substance use strategy was removed so as not to contaminate the analyses.)

The final model of the first analysis, explaining $24 \%$ of the variance, indicated that the behavior of smoking was negatively associated with positivity and with use of emotional support, and positively associated with age, positive reevaluation, and venting of emotions. The final model of the second analysis, explaining $19 \%$ of the variance, indicated that alcohol use was negatively associated with positivity and positively associated with the strategies of spirituality and denial.

Table 3. Final models of the stepwise multiple regression analyses, taking gender, age, positivity and coping strategies as predictive variables, and tobacco and alcohol use as criteria.

\begin{tabular}{lccc}
\hline Tobacco use & $\mathrm{B}$ & SEB & $\beta$ \\
\hline Age & 0.14 & 0.04 & $0.28^{* *}$ \\
Positivity & -0.03 & 0.01 & $-0.27^{* *}$ \\
Positive Reevaluation & 0.12 & 0.05 & $0.22^{*}$ \\
Use of Emotional Support & -0.13 & 0.05 & $-0.26^{* *}$ \\
Venting of emotions & 0.11 & 0.04 & $0.25^{* *}$
\end{tabular}

Adjusted $\mathrm{R}^{2}$ model $=0.24 ; \mathrm{F}(5,100)=7.44 * * *$

\begin{tabular}{lccc}
\hline \multicolumn{1}{c}{ Alcohol use } & $\mathrm{B}$ & $\mathrm{SEB}$ & $\beta$ \\
\hline Positivity & -0.04 & 0.01 & $-0.30^{* * *}$ \\
Spirituality & 0.17 & 0.07 & $0.24^{* *}$ \\
Denial & 0.13 & 0.05 & $0.22^{*}$
\end{tabular}

Adjusted $\mathrm{R}^{2}$ model $=0.19 ; \mathrm{F}(3,102)=9.03^{* * *}$

Note: $* \mathrm{p}<0.05 ; * * \mathrm{p}<0.01 ; * * * \mathrm{p}<0.001$ 


\section{Discussion}

With regard to our first objective, results from the present study show significant relationships between coping strategies, positivity and tobacco and alcohol use, as well as the modulating role of age and gender. In the first case, positivity is negatively associated with tobacco and alcohol use and the use of non-adaptive coping strategies (substance use and blaming self) and positively associated with coping styles that are oriented toward solving difficulties. The pattern of results clearly suggests the protective value of the positivity dimension for health; this result is consistent with the available evidence that indicates a beneficial effect associated with optimism, life satisfaction, and self-esteem, elements that make up the positivity dimension (Alessandri, Caprara et al., 2012). Also in line with former research on the topic, our data regarding the association between coping strategies and tobacco and alcohol use suggests a connection between substance use and a non-adaptive coping style, where one avoids dealing with the problem, evading it, denying it, or leaving its solution to other external factors, as may be the case in our study where one appeals to religious beliefs or practices (Dugan, Lloyd \& Lucas, 1999; Gómez-Fraguela et al., 2006; Wagner, Myers \& McIninch, 1999; Wills \& Hirky, 1996). In the latter case, while research on the role of this coping strategy is still inconclusive (Carver, Scheier \& Weintraub, 1989; Eisenberg et al., 2011; Frydenberg \& Lewis, 1991), our results suggest a negative effect of this strategy when it is actually being used to avoid dealing with problems.

Secondly, regarding the modulating role of individual age and gender differences, results from our study support the existing evidence that tobacco and alcohol use increase with age, as well as adolescents' greater inclination toward coping strategies that seek to manage the tension and emotional discomfort produced by problems. However, the results are less conclusive about the differential effect of gender on levels of tobacco and alcohol use (Carver \& Connor-Smith, 2010; Gómez-Fraguela et al., 2006; González-Barrón et al. 2002; Ramos \& Moreno, 2010).

In order to address our second objective, and to suggest the pattern of interrelationships considered in response to the first objective with greater explanatory power, we look to the results from our regression analyses. First, in line with the preexisting research on the topic (Caprara, Alessandri, Eisenberg et al., 2012), positivity is one of the most predictive factors 
of substance use behaviors, such that having a positive attitude toward oneself, toward one's life and toward the future seems to act as a protective factor, decreasing the likelihood that the adolescent will begin to use tobacco and alcohol. Second, at the other end, facing difficulties using strategies that attempt to decrease tension and stress without directly addressing the problems (venting of emotions in order to offload negative feelings, denying the problem or seeking refuge in religious practices) seems to facilitate substance use (see review in Wills \& Hirky, 1996). Third, the personal, social and contextual changes associated with age increase the risk of initiation in substance use, at least in the case of tobacco (Ebata \& Moos, 1994). Worthy of further mention is the behavior of the strategies positive reevaluation and use of emotional support. Regarding the first, often considered a productive strategy that facilitates adaptive behavior, positive reevaluation may also act as a negative strategy, as occurred in our study, to the extent that it reflects excessive optimism that would lead the adolescent to ignore the risk associated with substance use (Arnett, 2000). In contrast, facing problems by seeking emotional support in others is often considered an ineffective strategy for solving problems; however, it may have positive effects, to the extent that the control of emotionality that is gained through support from others can help the subject to consider the situation more carefully, and find effective strategies to deal with it (Carver, et al., 1989).

Possible limitations of our study include its cross-sectional nature and the use of selfreport measurements for assessing the different variables. It is well known that the former makes it difficult to identify causality relationships among the factors; therefore, we must call for longitudinal research that would make it possible to identify the existence and direction of potential causal relationships. On the other hand, in order to avoid a self-reporting bias, future studies should complement such measures with other assessment strategies (e.g. interviews), use of other-reported data, or objective measurements in the case of behavioral variables. Finally, the use of a non-random sample in our study advises caution when considering the possibility of generalizing results.

Despite these limitations, the present study offers additional evidence to our body of knowledge about the relationships between coping strategies and tobacco and alcohol use in adolescents, as well as the effect of individual differences based on gender and age. Secondly, new data from Spain are made available in connection with the role of the new construct positivity. From this perspective, we find a new channel for designing intervention strategies for preventing the initiation of substance use and for reinforcing the development, well-being and 
health of adolescents. For this purpose, the school offers a suitable setting for developing programs that aim to make students aware of the risk associated with use of tobacco, alcohol and other addictive substances, to teach them to identify situations that may lead to initiation of substance use, to train them in strategies for resisting social pressure, mainly from one's group of friends, in other words, equip them with psychosocial resources (potentialities, attitudes, expectations, etc.) that help them adaptively deal with the different challenges that are present in their daily life, including those that may seriously threaten their physical and psychological health and well-being. 


\section{References}

Abernathy, T.J., Massad, L. \& Romano-Dwyer, L. (1995). The relationship between smoking and self-esteem. Adolescence, 30, 899-907.

Alessandri, G., Caprara, G. V. \& Tisak, J. (2012). The unique contribution of positive orientation to optimal functioning. European Psychologist, 17, 44-54. doi: http://dx.doi.org/10.1027/2F1016-9040/Fa000070

Alessandri, G., Vecchione, M., Tisak, J., Deiana, G., Caria, S. \& Caprara, G.V. (2012). The utility of positive orientation in predicting job performance and organisational citizenship behaviors. Applied Psychology: An International Review, 61, 669-698. doi: http://dx.doi.org/10.1111/j.1464-0597.2012.00511.x

Arnett, J.J. (2000). Optimistic bias in adolescent and adult smokers and nonsmokers. Addictive Behaviors, 25, 625-632. doi: http://dx.doi.org/10.1016/S0306-4603(99)00072-6

Bindorf, S., Ryan, S., Auinger, P. \& Aten, M. (2005). High self-esteem among adolescents: Longitudinal trends, sex differences and protective factors. Journal of Adolescent Health, 37, 194-201. doi: http://dx.doi.org/10.1016/j.jadohealth.2004.08.012

Boman, P., Smith, D.C. \& Curtis, D. (2003). Effects of pessimism and explanatory style on development of anger in children. School Psychology International, 24, 80-94. doi: http://dx.doi.org/10.1177/0143034303024001581

Caprara, G.V., Alessandri, G., Eisenberg, N., Kupfer, A., Steca, P., Caprara, M.G., Yamaguchi, S., Fukuzawa, A. \& Abela, J. (2012). The Positivity Scale. Psychological Assessment, 24, 701-712. doi: http://dx.doi.org/10.1037/a0026681

Caprara, G.V., Alessandri, G., Trommsdorff, G., Heikamp, T., Yamaguchi, S. \& Suzuki, F. (2012). Positive orientation across three cultures. Journal of Cross-Cultural Psychology, 43, 77-83. doi: http://dx.doi.org/10.1177/0022022111422257

Caprara, G. V., Steca, P., Alessandri, G., Abela, J. R. Z. \& McWhinnie, C. M. (2010). Positive Orientation: Explorations of what is common to Life Satisfaction, Self-Esteem, and Optimism. Epidemiology and Psychiatric Sciences, 19, 63-71. doi: http://dx.doi.org/10.1017/S1121189X00001615

Carvajal, S.C. (2012). Global positive expectancies in adolescence and health-related behaviours: Longitudinal models of latent growth and cross-lagged effects. Psychology \& Health, 27, 916-937. doi: http://dx.doi.org/10.1080/08870446.2011.633241

Carvajal, S.C., Evans, R.I., Nash, S.G. \& Getz, J.G. (2002). Global positive expectancies of the self and adolescents' substance use avoidance: Testing a social influence mediational 
model. Journal of Personality, 70, 421-442. doi: http://dx.doi.org/10.1111/1467$\underline{6494.05010}$

Carver, C. S. (1997). You want to measure coping but your protocol's too long: Consider the Brief COPE. International Journal of Behavioral Medicine, 4, 92-100. doi: http://dx.doi.org/10.1207/s15327558ijbm0401_6

Carver, C. S. \& Connor-Smith, J. (2010). Personality and coping. Annual Review of Psychology, 61, 679-704. doi: http://dx.doi.org/10.1146/annurev.psych.093008.100352

Carver, C.S. \& Scheier, M.F. (2002). Optimism. In C.R. Snyder \& J.L. Lopez (Eds.), Handbook of Positive Psychology (pp. 231-243). New York: Oxford University Press.

Carver, C. S., Scheier, M. F. \& Segerstrom, S. C. (2010). Optimism. Clinical Psychology Review, 30, 879-889. doi: http://dx.doi.org/10.1016/j.cpr.2010.01.006

Carver, C.S., Scheier, J. \& Weintraub, J. (1989). Assessing coping strategies: A theoretically based approach. Journal of Personality and Social Psychology, 56, 267-283. doi: http://dx.doi.org/10.1037/0022-3514.56.2.267

Diener, E. (1984). Subjective well-being. Psychological Bulletin, 95, 542-575. doi: http://dx.doi.org/10.1037/0033-2909.95.3.542

Diener, E. \& Chan, M. Y. (2011). Happy people live longer: Subjective well-being contributes to health and longevity. Applied Psychology: Health and Well-Being, 3, 1-43. doi: http://dx.doi.org/10.1111/j.1758-0854.2010.01045.x

Diener, E., Emmons, R.A., Larsen, R.J. \& Griffin, S. (1985). The satisfaction with life scale. Journal of Personality Assessment, 49, 71-75. doi: http://dx.doi.org/10.1207/s15327752jpa4901_13

Dugan, S., Lloyd, B. \& Lucas, K. (1999). Stress and coping as determinants of adolescent smoking behaviour. Journal of Applied Social Psychology, 29, 870-888. doi: http://dx.doi.org/10.1111/j.1559-1816.1999.tb02030.x

Ebata, A.T. \& Moos, R.H. (1994). Personal, situational, and contextual correlates of coping in adolescence. Journal of Research on Adolescence, 4, 99-125. doi: http://dx.doi.org/10.1207/s15327795jra0401_6

Eisenberg, N., Castellani, V., Panerai, L., Eggum, N.D., Cohen, A.B., Pastorelli, C. \& Caprara, G. V. (2011). Trajectories of religious coping from adolescence into early adulthood: Their form and relations to externalizing problems and prosocial behavior. Journal of Personality, 79, 841-873. doi: http://dx.doi.org/10.1111/j.1467-6494.2011.00703.x

Eisenberg, S.A., Shen, B.J., Schwarz, E.R. \& Mallon, S. (2012). Avoidant coping moderates the association between anxiety and patient-rated physical functioning in heart failure pa$-362-$ 
tients. Journal of Behavioral Medicine, 35, 253-261. doi: http://dx.doi.org/10.1007/s10865-011-9358-0

Emler, N. (2001). Self-esteem: The costs and consequences of low self-worth. York, England: York.

Frydenberg, E. \& Lewis, R. (1991). Adolescent coping styles and strategies: Is there functional and dysfunctional coping? Journal of Counseling and Guidance, 1, 35-43.

Gentile, B., Grabe, S., Dolan-Pascoe, B., Twenge, J.M. \& Wells, B.E. (2009). Gender differences in domain-specific self-esteem: A meta-analysis. Review of General Psychology, 13, 34-45. doi: http://dx.doi.org/10.1037/a0013689

Gilman, R., Huebner, E.S., Tian, L., Park, N., O`Byrne, J., Schiff, M., Sverko, D., \& Langknecht, H. (2008). Cross-National Adolescent Multidimensional Life Satisfaction Reports: Analyses of mean scores and response style differences. Journal of Youth and Adolescence, 37, 142-154. doi: http://dx.doi.org/10.1007/s10964-007-9172-8

Glaesmer, H., Risf, W., Martin,A., Mewes, R., Brähler, E., Zenger, M. \& Hinz, A. (2012). Psychometric properties and population-based norms of the Life Orientation Test Revised (LOT-R). British Journal of Health Psychology, 17, 432-445. doi: http://dx.doi.org/10.1111/j.2044-8287.2011.02046.x

Goldbeck, L., Schmitz, T.G., Besier, T., Herschbach, P. \& Henrich, G. (2007). Life satisfaction decreases during adolescence. Quality of Life Research, 16, 969-979. doi: http://dx.doi.org/10.1007/s11136-007-9205-5

Gómez-Fraguela, J. A., Luengo, A., Romero, E., Villar, P. \& Sobral, J. (2006). Estrategias de afrontamiento en el inicio de la adolescencia y su relación con el consumo de drogas y la conducta problemática. [Coping strategies at the start of adolescence and their relation with drug use and problema behavior.] International Journal of Clinical and Health Psychology, 6, 581-597.

González-Barrón, R., Montoya I., Casullo, M. \& Bernabéu, J. (2002). Relación entre estilos y estrategias de afrontamiento y bienestar psicológico en adolescentes. [Relation between coping styles and strategies and psychology well-being in adolescents.] Psicothema, 14, 363-368.

Huan, V.S., Yeo, L.S., Ang, R.P. \& Chong, W.H. (2006). The influence of dispositional optimism and gender on adolescents' perception of academic stress. Adolescence, 41, 533546. 
Kling, K.C., Hyde, J.S., Showers, C.J. \& Buswell, B.N. (1999). Gender differences in selfesteem: A meta-analysis. Psychological Bulletin, 125, 470-500. doi: http://dx.doi.org/10.1037/0033-2909.125.4.470

Lazarus, R.S. \& Folkman, S. (1986). Estrés y procesos cognitivos. [Stress and cognitive processes.] Barcelona: Martínez Roca.

Major, B., Barr, L., Zubek, J. \& Babey, S.H. (1999). Gender and self-esteem: A metaanalysis. In W.B. Swann Jr., J.H. Langlois \& L.A. Gilbert (Eds.), Sexism and stereotypes in modern society: The gender science of Janet Taylor Spence (pp. 223-253). Washington, DC: American Psychological Association.

Martín, G., Lucas, B. \& Pulido, R. (2011). Diferencias de género en el afrontamiento en la adolescencia. [Gender differences in coping in adolescence.] Brocar, 35, 157-166.

Masferrer, L., Font-Mayolas, S. \& Gras, M. E. (2012). Satisfacción con la vida y consumo de sustancias psicoactivas en la adolescencia. [Satisfaction with life and use of psychoactive substances in adolescence.] Cuadernos de Medicina Psicosomática y Psiquiatría de Enlace, 102, 47-53.

Morán, C., Landero, R. \& González, M. T. (2010). COPE-28: un análisis psicométrico de la versión en español del Brief COPE. [COPE-28: a psychometric analysis of the Spanish versión of the Brief COPE] Universitas Psychologica, 9, 543-552.

Myers, M.G. \& MacPherson, L. (2009). Coping with temptations and adolescent smoking cessation: An initial investigation. Nicotine and Tobacco Research, 11, 940-944. doi: http://dx.doi.org/10.1093/ntr/ntp089

Otten, R., Van Lier, P.A.C. \& Engels, R. (2011). Disentangling two underlying processes in the initial phase of substance use: Onset and frequency of use in adolescent smoking. $A d$ dictive Behaviors, 36, 237-240. doi: http://dx.doi.org/10.1016/j.addbeh.2010.10.003

Parker, J.D. \& Endler, N.S. (1996). Coping and defense: A historical overview. In M. Zeidner \& N.S. Endler (Eds.), Handbook of Coping. Theory, Research, Applications (pp. 3-23). New York: John Wiley \& Sons.

Piko, B.F., Luszczynska, A., Gibbons, F.X. \& Teközel, M. (2005). A culture-based study of personal and social influences of adolescent smoking. European Journal of Public Health, 15, 393-398. doi: http://dx.doi.org/10.1093/eurpub/cki008

Plan Nacional sobre Drogas [National Plan on Drugs.] (2010). Informe de la Encuesta Estatal sobre Uso de Drogas en Estudiantes de Enseñanzas Secundarias (ESTUDES) 2010. [Report from the State Survey on Drug Use in Secondary Students. 2010.] Madrid: Ministerio de Sanidad, Política Social e Igualdad. 
Puskar, K.R., Bernardo, L.M., Ren, D., Haley, T.M., Tark, K.H., Switala, J. \& Simeon, L. (2010). Self-esteem and optimism in rural youth: Gender differences. Contemporary Nurse, 34, 190-198. doi: http://dx.doi.org/10.5172/conu.2010.34.2.190

Ramos, P. \& Moreno, C. (2010). Situación actual del consumo de sustancias en los adolescentes españoles: tabaco, alcohol, cannabis y otras drogas ilegales. [Current situation of substance use in Spanish adolescents: tobacco, alcohol, cannabis and other illegal drugs.] Health and Addictions, 10, 13-36.

Rosenberg, M. (1965). Society and the adolescent self-image. New Jersey: Princeton University Press.

Scheier, M.F. \& Carver, C.S. (1985). Optimism, coping, and health: Assessment and implications of generalized outcome expectancies. Health Psychology, 4, 219-247. doi: http://dx.doi.org/10.1037/0278-6133.4.3.219

Twenge, J.M. \& Campbell, W.K. (2001). Age and birth cohort differences in self-esteem: A cross-temporal meta-analysis. Personality and Social Psychology Review, 5, 321-344. doi: http://dx.doi.org/10.1207/S15327957PSPR0504_3

Wagner, E.F., Myers, M.G. \& McIninch, J.L. (1999). Stress-coping and temptation-coping as predictors of adolescent substance abuse. Addictive Behaviors, 24, 769-779. doi: http://dx.doi.org/10.1016/S0306-4603(99)00058-1

Wills, T.A. \& Hirky, A.E. (1996). Coping and substance abuse: A theoretical model and review of the evidence. In M. Zeidner \& N.S. Endler (Eds.), Handbook of Coping. Theory, Research, Applications (pp. 279-302). New York: John Wiley \& Sons.

Zullig, K.J., Valois, R.T., Huebner, E.S., Oeltmann, J.E. \& Drane, W. (2001). Relationship between perceived life satisfaction and adolescents' substance abuse. Journal of Adolescent Health, 29, 279-288. doi: http://dx.doi.org/10.1016/S1054-139X(01)00269-5 
$M^{\mathrm{a}}$. Dolores Lara et al.

[This page intentionally left blank] 